\title{
Effects of educational intervention on knowledge and attitude on early detection of breast cancer
}

\author{
Efeitos de intervenção educativa no conhecimento e atitude sobre detecção precoce do \\ câncer de mama
}

Pricilla Cândido Alves ${ }^{1}$, Iarlla Silva Ferreira ${ }^{1}$, Míria Conceição Lavinas Santos ${ }^{1}$, Adrielle Oliveira Azevedo de Almeida ${ }^{1}$, Ana Fátima Carvalho Fernandes ${ }^{1}$

objective: to compare the knowledge and attitude of women in relation to the early detection of breast cancer, before and after the application of educational intervention. Methods: a quasi-experimental study was conducted with 91 women. Through the application of educational intervention, women were divided into four groups of health education. The educational material used was an informative folder on the early detection of breast cancer, associated to the brief motivational interview technique. Results: the educational intervention associated to the brief motivational interview promoted an increase in the adequacy of knowledge $(p=0.001)$ and attitude $(p=0.007)$. Conclusion: the educational intervention was able to increase the percentage of adequacy of the knowledge and the attitude of women in relation to the early detection of breast cancer.

Descriptors: Knowledge; Attitude; Breast Neoplasms; Secondary Prevention; Motivational Interviewing.

Objetivo: comparar conhecimento e atitude de mulheres em relação à detecção precoce do câncer de mama, antes e após aplicação de intervenção educativa. Métodos: estudo quase-experimental, realizado com 91 mulheres. Através da aplicação de intervenção educativa, as mulheres foram divididas em quatro grupos de educação em saúde. 0 material educativo utilizado foi um folder informativo sobre detecção precoce do câncer de mama, associado à técnica de entrevista motivacional breve. Resultados: a intervenção educativa associada à entrevista motivacional breve promoveu aumento da adequação do conhecimento $(\mathrm{p}=0,001)$ e da atitude $(p=0,007)$. Conclusão: a intervenção educativa foi capaz de elevar o percentual de adequabilidade do conhecimento e da atitude de mulheres em relação à detecção precoce do câncer de mama.

Descritores: Conhecimento; Atitude; Neoplasias da Mama; Prevenção Secundária; Entrevista Motivacional.

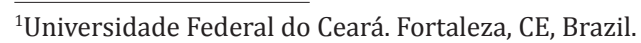




\section{Introduction}

The estimates of the National Cancer Institute for each year of the 2018-2019 biennium reveal the record of about 59,700 new cases of breast cancer in Brazil, with an estimated risk of 56.33 cases per 100,000 women $^{(1)}$. The incidence of the disease has increased in most regions of the world, especially in low and middle income countries, whose diagnosis of breast cancer occurs in more advanced stages and, therefore, has been one of the priorities in the National Policy of Health in Brazil and the Ministry of Health recommends the identification of the disease in the early stages, through early detection strategies that include screening and early diagnosis ${ }^{(2)}$.

Screening involves the investigation of cancer in asymptomatic individuals and involves the mammography and clinical examination of the breasts, while the early diagnosis represents the identification of people with signs and symptoms of breast cancer as early as possible, standing out as actions of early diagnosis the women's awareness strategies, so that they are well informed and attentive to possible changes in the breasts, seeking promptly the health service, in case of abnormalities ${ }^{(3)}$.

Nursing, through human training and focused on health education, can effectively contribute to this process of awareness and knowledge about the disease, since health education is part of the nursing action as a promising strategy in facing the multiple problems of affecting populations and their social contexts ${ }^{(4)}$.

Although the educational interventions used in the nursing and breast cancer context have produced positive results in terms of increased knowledge, information multiplication, as well as changes and adoption of behaviors suitable for early diagnosis ${ }^{(5-6)}$ and mortality rates have declined in the last decade, the numbers are still considered high, with breast cancer being the leading cause of cancer death among women $^{(1,3)}$, reinforcing the need to the development of interventions and more effective strategies for early detection of the disease.
Given the need to inform and mobilize the population for the success of early detection of breast cancer, and the lack of knowledge about early detection methods is one of the factors contributing to the high mortality rates of the disease $\mathrm{e}^{(2)}$, it is believed that the implementation of educational actions aimed at the early detection of breast cancer may lead to improvements in the achievement of the goals and targets proposed by the programs for tracking and combating the disease.

The motivational interview, a technique aimed at behavior change ${ }^{(7)}$, has shown effective results, in what refers to the development of actions directed at the greater commitment of women to preventive and breast health care practices, to evaluate the effectiveness of a breast cancer screening program, which used the motivational interview as an intervention, including home visits and telephone follow-up of women who had not had a mammogram for two years, with a $10.0 \%$ increase in mammography screening in the intervention group ${ }^{(8)}$.

When considering the promising effects that can be achieved in relation to a given objective, from the simple provision of information in a differentiated way, in which the client is sought as a focus, motivating him to use his own autonomy in the search for appropriate behavior, are the benefits of using the motivational interview, associated to educational interventions, in the scope of actions for the early detection of breast cancer are very positive. Thus, the study becomes relevant, since it can increase improvements in the achievement of the goals proposed by the programs for tracking and combating the disease, since the population's awareness about the disease and the stimulus to the changes of behavior are fundamental actions for the control of this, besides having implications for educational practices in Nursing.

In view of the above, the objective was to compare the knowledge and attitude of women in relation to the early detection of breast cancer, before and after the application of educational intervention. 


\section{Methods}

A quasi-experimental study, of the before-and-after kind, performed in 2014, in a gynecology clinic of a private tertiary hospital, located in Porto Alegre, RS, Brazil. For the sample calculation, a confidence level of $95.0 \%$, power of $80.0 \%$, and difference in at least $20.0 \%$ of the outcome, knowledge and attitude variables, before and after the intervention, resulted in a minimum sample of 120 participants. The inclusion criteria for the study were: women with ages above 18 years and who attended the study site to perform gynecological care. Women with no schooling, who had previous history of breast cancer, who were not able to answer the research questions due to age or difficulty in communication were excluded from the sample.

The study data were collected in three stages. The initial stage consisted of the pre-test with the participants, through the application of the instrument, with data regarding knowledge and attitude regarding the early detection of breast cancer; and the interview form, with demographic and socioeconomic data to characterize the profile of women. The instrument on knowledge and attitude was constructed by the author, with the collaboration of three specialists, nursing professors and researchers on breast cancer, a pilot test was carried out with 12 participants who were at the collection site and were not the same included in the survey. It had as its main axis the knowledge and attitude regarding the early detection of breast cancer (clinical examination of the breasts and mammography). The evaluation of knowledge and attitude regarding the early detection of breast cancer occurred according to criteria based on an earlier stu$\mathrm{dy}^{(6)}$, classified as adequate and inadequate according to the following criteria:

Adequate knowledge: when the participant responded that it was possible to detect breast cancer early, that this detection occurred through the periodic exams; when she had heard about early breast cancer screening exams and knew how to define each exam and how old they should be. Inadequate knowledge: when the participant mentioned that breast cancer could not be detected early, when she said that breast cancer could be detected early, but that she mentioned other exams rather than breast examination and mammography, when she said that she had never heard talk about the early detection tests or when she said she heard about the exams, but she did not know how to define them. In order for the knowledge of the woman in relation to the early detection of breast cancer to be considered adequate, it should respond correctly to all the knowledge items.

Adequate attitude: when the participant affirmed that she should perform the tests of early detection of breast cancer and had as motivation to perform these tests: early detection, a routine examination or the search for adequate health for the breasts. Inadequate Attitude: When the woman reported that she should not perform the tests for early detection of breast cancer, when she had other reasons for performing the test that were not the early diagnosis of the disease, or even said that she felt unmotivated to perform the tests.

In this first stage, the participants were selected for convenience, from initial contact in the waiting room of the gynecology outpatient clinic of the referred hospital, inviting them to participate in the research and explaining the objectives of the study. As the women agreed to participate, the Free and Informed Consent Form was signed and they were taken to the study room of the research site for application of the interview form and instrument on knowledge and attitude towards the early detection of breast cancer, in order to have a baseline in relation to the outcomes studied. The application of these instruments lasted on average 20 minutes, were applied by the principal investigator and two previously trained Nursing students. After applying the pre-test, the participants were informed that they would receive telephone contact to participate in the second stage of the study (Educational Intervention). 120 participants participated in the first stage, requiring six visits to the 
research site for the recruitment of this number of subjects.

In the second stage of the study, the telephone contact with the participants was carried out one week before the intervention, with 29 participants reporting the impossibility of attending this second moment for various reasons (loss of 24.1\%). Thus, 91 participants participated in the second stage. The application of the educational intervention associated to the motivational interview was carried out in health education groups with duration of four hours, occurring in four different days, in the study room located in the same physical space of the gynecology outpatient clinic. Participants were divided into four groups, three groups with 22 women and one group with 25 participants, totaling the 91 participants in the study. The topics discussed during the educational intervention covered information related to breast cancer, early detection and control of the disease. There was no use of recorders and audio/visual feature. The researcher and two trained Nursing students participated in this study.

The educational material used was an informative folder, developed by the National Cancer Institute, as part of the population coverage actions of the National Breast Cancer Control Program ${ }^{(9)}$, which shows images of women in different age groups, showing that the disease can affect women at all ages, as well as information on the definition of breast cancer, early detection, definition of early detection tests and the age range to be performed, warning signs on the disease and breast health guidelines. After distribution and reading of the educational material by the women, verbal guidance was given by the researchers and elucidation of the questions and doubts of the participants, and the brief motivational interview technique was carried out with the explanations given to the women, with the objective of stimulating and motivate beneficial health actions in relation to the early detection of the disease.

The motivational interview uses the motivation, energy and commitment of the individual to de- sired behavioral change. The technique was based on elements of other existing techniques, such as client-centered therapy, described as a collaborative, evocative approach with respect for the autonomy of the person $^{(7)}$. It was decided to use this technique in this study, considering that behavior change, the adoption of appropriate attitudes towards early detection of breast cancer are fundamental actions to achieve the goals proposed by the breast cancer screening programs. The training for applying the brief motivational interview technique was given by a researcher from the area, at Pontifícia Universidade Católica, RS, Brazil.

The brief motivational interview was conducted in a single meeting with participants from each of the four groups. The application of this consisted in advising and clarifying the goals and importance of the knowledge and realization by the woman of the examinations of early detection of breast cancer, besides emphasizing the positive attitude benefits in relation to the control of the disease. The inform-verify-inform strategy ${ }^{(7)}$ was used, in which the professional provides information on a certain subject, verifies if the person understood and provides more information until the completeness of the subject addressed has occurred.

The third stage of the study was equivalent to the application of the immediate post-test to evaluate the knowledge and attitude regarding the early detection of breast cancer, after educational intervention, associated to the motivational interview. For this study, it was opportune to guarantee the partial evaluation (immediate post-test), despite the risk of bias for the findings, considering the short time interval for the measurement of the intervention results, due to the possibility of more follow-up losses in it is also pertinent to partially evaluate the results after the intervention, since the effectiveness indicator during an evaluation process considers relevant the application of partial evaluations at the end of the stages of a program/intervention ${ }^{(10)}$.

Data were compiled and analyzed through the Statistical Package for the Social Sciences program, 
version 21.0. Mean and standard deviation were calculated for continuous variables, in addition to the frequency distribution for categorical variables. Pearson's Chi-square $\left(\mathrm{x}^{2}\right)$ test was used to compare the knowledge and attitude data regarding the early detection of breast cancer, before and after applied intervention, and the value of $p<0.05$ as statistically significant.

The study complied with national and international guidelines and standards for research involving human subjects. The research was approved by the Research Ethics Committee of the Federal University of Ceará, Brazil, according to no 369,590/2013 and Certificate of Presentation for Ethical Appreciation no. $13790713,0,0000,5054$. Participants were clarified about the purpose of the study, agreed and signed the Informed Consent Term.

\section{Results}

A total of 91 women participated in the study, with a loss of $24.1 \%$ among the 120 initially eligible participants. The mean age of participants was 44.24 years (standard deviation (SD) $= \pm 14.8$ years). The schooling, measured in years of study, obtained a mean of 15.37 years ( $S D= \pm 3.37$ years). The average income was $\mathrm{R} \$: 4,357.89$ ( $\mathrm{SD}= \pm 2,680.00$ ). Most of the women had a companion (73.6\%) and had predominant occupation of the home (50.5\%).

Regarding the personal and family history, the mean age of the menarche was 12.65 years (SD \pm 1.8 ). The mean age of menopause was 49.09 years (SD \pm 5.03 ). The mean duration of breastfeeding was 13.91 months (SD \pm 10.97 ). Of the 91 participants, $68(74.7 \%)$ had at least one lifetime pregnancy, 58 $(84.1 \%)$ breastfed and the mean age of the first gestation was 24.10 years ( $S D \pm 5.55$ ). Most of the women, 67 (73.6\%), reported not having used contraceptives throughout their lives. Of the 24 (26.4\%) who used, the mean time of use was 115.46 months (SD \pm 87.34 ).

Regarding knowledge about the early detection of breast cancer before the educational intervention,
$88(96.7 \%)$ of the women presented inadequate knowledge, with $3(3.3 \%)$ of the participants with adequacy. After applying the educational intervention, the percentage of women with knowledge adequacy was $74(81.3 \%)$, that is, the intervention was able to increase the knowledge adequacy percentage of $78.0 \%$, according to Table 1 . Pearson's $\mathrm{x}^{2}$ test demonstrated statistical significance in relation to knowledge change after intervention ( $\mathrm{p}=0.001)$.

Regarding attitude, there was a high percentage of women with adequate attitude before the intervention, 84 (92.2\%). After applying the educational intervention, there were $91(100.0 \%)$ of the participants with attitude adjustment. The increase in attitude change among women was $7.8 \%$ in relation to the percentage before the intervention. Pearson's $x^{2}$ test presented statistical significance $(\mathrm{p}=0.007)$, in the increase verified (Table 1).

Table 1 - Assessment of the adequacy and inadequacy of participants' knowledge and attitude about the early detection of breast cancer, before and after educational intervention

\begin{tabular}{|c|c|c|c|}
\hline \multirow{2}{*}{ Variables } & Pre-test & Post-test & \multirow{2}{*}{$\mathbf{p}^{*}$} \\
\hline & n (\%) & n (\%) & \\
\hline Knowledge & & & 0.001 \\
\hline Appropriate & $3(3.3)$ & 74 (81.3) & \\
\hline Inappropriate & 88 (96.7) & 17 (18.7) & \\
\hline Attitude & & & 0.007 \\
\hline Appropriate & $84(92.2)$ & $91(100.0)$ & \\
\hline Inappropriate & $7(7.7)$ & - & \\
\hline
\end{tabular}

\section{Discussion}

As limitations of this study, we highlight the absence of control group and immediate post-test, although there have been positive results using the brief motivational interview, in a single session with each group of participants, it is believed that the bond and empathy generated by the professional are capable of producing better effects on long-term knowledge and 
attitude as more customer encounters take place.

The promising findings of studies with approaches related to the use of motivational interview $^{(11-12)}$, regarding the adoption of healthy behaviors by the individuals, allows to understand that the information transmitted in a differentiated way can generate beneficial actions and preventive behaviors to the receivers. Thus, the association of the provision of information on the early detection of breast cancer, with the use of motivational interviewing, may justify, in the on-screen study, an increase in the adequacy of knowledge and attitude among women.

This study brings contributions, since nurses play a fundamental role in promoting the health of these women, being their primary involvement in the health-disease process, whose application of educational strategies and practices promoting health assume a prominent position. The contribution of educational strategies in the acquisition of knowledge involves health promotion, prevention of complications, development of abilities and favoring the autonomy of the patient, being extremely important the role of nurses as health educators, since they are able to use innovative strategies and associate techniques so that the information is provided in a differentiated way to the community.

The findings found in this study are supported by other studies that have also shown promising results in increasing women's knowledge about breast cancer, risk factors and diagnostic methods for early detection from the use of educational strategies ${ }^{(13-15)}$. It should be noted that different educational strategies were proposed in these studies, such as the development of focus groups, the application of an educational manual, a community intervention program, and others.

This research used as an educational intervention the folder associated to the motivational interview, which has provided more advantageous results in the acquisition of knowledge, since it transmits information and orientations in a refined way, guides the goals to be reached, provides professionals who use this technique to join the individuals to appropriate health behaviors and greater accumulation of information and knowledge by the subjects, precisely because it allows the transmission of information in a differentiated, empathetic and customer-centered way ${ }^{(11)}$.

In relation to the attitude, there was an increase in the motivation to seek appropriate behavior for breast health, through the detection tests among the participants who, initially, had not been motivated. This was also evidenced by a survey conducted in Bangladesh, which identified that although there was awareness among women about breast cancer, there was low uptake for tracking the disease. However, the implementation of health education programs, with emphasis on the importance of screening in asymptomatic women, has shown a high potential to modify the behavior of these women by raising awareness and, consequently, reducing the number of cases of breast cancer ${ }^{(16)}$.

Research in sub-Saharan Africa has also shown an increase in breast cancer-related behaviors, improving the knowledge and understanding of African women, thus facilitating the early detection of the disease $^{(17)}$.

The information about the magnitude of the risk is important, so that it is aware of this, revealing that the term breast cancer is typically associated with public campaigns that may be effective, increasing the awareness of the population, but sometimes they are not effective in motivate women to seek preventive and disease control treatments ${ }^{(14)}$, which was not observed in this study, since most of the participants presented an adequate attitude regarding the early detection of breast cancer.

Interventions that focus on preventive practices and that value communication and information as key points in the patient's approach should be concei- 
ved considering cultural, cognitive aspects and capacities of those involved. These characteristics are all included in the motivational interview, which has been used successfully to promote adherence and acquisition of differentiated behaviors in several areas ${ }^{(12)}$.

Increased knowledge about breast cancer and early detection exams provide health motivation and may influence the practice of breast cancer awareness, e.g. intensification of breast cancer awareness may promote the early detection of breast cancer. Therefore, the information is fundamental, because it generates the possibility of new perspectives ${ }^{(11)}$.

\section{Conclusion}

The application of the educational intervention was able to raise the percentage of adequacy of the knowledge and attitude of women in relation to the early detection of breast cancer.

\section{Acknowledgments}

To the Conselho Nacional de Desenvolvimento Científico e Tecnológico, for the grant of a Research Productivity grant to Ana Fátima Carvalho Fernandes, process no 301943/2017-6.

\section{Collaborations}

Alves PC, Santos MCL and Fernandes AFC contributed with project design, analysis and interpretation of the data and final approval of the final version to be published. Ferreira IS and Almeida AOA collaborated with article writing and critical review of intellectual content.

\section{References}

1. Instituto Nacional do Câncer José Alencar da Silva. Estimativas 2018: incidência de câncer no Brasil [Internet]. 2018 [citado 2019 mar. 16]. Disponível em: http://www.inca.gov.br/estimativa/2018
2. Instituto Nacional do Câncer José Alencar da Silva. Diretrizes para a detecção precoce do câncer de mama no Brasil [Internet]. 2015 [citado 2019 mar. 2]. Disponível em: http://www1.inca.gov.br/ inca/Arquivos/livro_deteccao_precoce_final.pdf

3. Facina T. Diretrizes para a detecção precoce do câncer de mama no Brasil. Rev Bras Cancerol [Internet]. 2016 [citado 2019 mar. 2]; 62(1):5960. Disponível em: www.inca.gov.br/rbc/n_62/ v01/pdf/10-resenha-diretrizes-para-a-deteccaoprecoce-do-cancer-de-mama-no-brasil.pdf

4. Melo MCSC, Souza, IEO. Ambiguidade-modo de ser da mulher na prevenção secundária do câncer de mama.EscAnnaNery.2012;16(1):41-8. doi:dx.doi. org/10.1590/S1414-81452012000100006

5. Lourenço TS, Mauad EC, Vieira RAC. Barreiras no rastreamento do câncer de mama e o papel da enfermagem: revisão integrativa. Rev Bras Enferm. 2013; 66(4):585-91. doi: http://dx.doi. org/10.1590/S0034-71672013000400018

6. Silva APS, Alexandre HG, Almeida PC, Ximenes LB, Fernandes AFC. Effects of an educational technology application in the early detection of breast cancer. Rev Rene. 2017; 18(3):404-11. doi: http://dx. doi.org/10.15253/2175-6783.2017000300017

7. Miller W, Rollnick S. Motivacional interviewing: preparing people for change. New York: The Guilford Press; 2002.

8. KvaleEA, HuangCHS, Meneses KM, WahnefriedWD, Bae S, Azuero CB, et al. Patient-centered support in the survivorship care transition: outcomes from the patient-owned survivorship care plan intervention. Cancer. 2016; 122(20):3232-42. doi: dx.doi.org/10.1002/cncr.30136

9. Instituto Nacional do Câncer José Alencar da Silva. Programa Nacional de Controle do Câncer de Mama [Internet]. 2011 [citado 2019 jan. 24]. Disponível em: http://www2.inca.gov.br/wps/ wcm/connect/acoes_programas/site/home/ nobrasil+/programa_controle_cancer_mama/

10. Sano H, Montenegro Filho MJF. As técnicas de avaliação da eficiência, eficácia e efetividade na gestão pública e sua relevância para o desenvolvimento social e das ações públicas. Desenv Quest [Internet]. 2013 [cited 2019 mar. 2]; 11(22):3561. Disponível em: www.revistas.unijui.edu.br/ index.php/desenvolvimentoemquestao/article/ view/186/54 
11. Spector D, Deal AM, Amos KD, Yang H, Battaglini CL. A pilot study of a home-based motivational exercise program for African American breast cancer survivors: clinical and quality-of-life outcomes. Integr Cancer Ther. 2014; 13(2):12132. doi: dx.doi.org/10.1177/1534735413503546

12. Borges SAC, Porto PN. Por que os pacientes não aderem ao tratamento? Dispositivos metodológicos para a educação em saúde. Saúde Debate. 2014; 38(101):338-46. doi: dx.doi.org/10.5935/01031104.20140031

13. Bushatsky M, Cabral LR, Cabral JR, Barros MBSC, Gomes BMR, Figueira Filho ASS. Educação em saúde: uma estratégia de intervenção frente ao câncer de mama. Cienc Cuid Saúde. 2015; 14(1):870-8. doi: http://dx.doi.org/10.4025/cienccuidsaude. v14i1.23259

14. Ramathuba DU, Ratshirumbi CT, Mashamba TM. Knowledge, attitudes and practices toward breast cancer screening in a rural South African community. Curationis. 2015; 38(1):1-8. doi: http://dx. doi.org/10.4102/curationis.v38i1.1172
15. Siddhart R, Grupta D, Narang R, Singh P. Knowledge, attitude and practice about breast cancer and breast self-examination among women seeking out-patient care in a teaching hospital in central India. Indian J Cancer. 2016; 53(2):226-9. doi: dx.doi.org/10.4103/0019-509X.197710

16. Islam RM, Bell RJ, Billah B, Hossain MB, Davis SR. Awareness of breast cancer and barriers to breast screening uptake in Bangladesh: a population based survey. Maturitas. 2016; 84:68-74. doi: https://doi.org/10.1016/j.maturitas.2015.11.002

17. Akuoko CP, Armah E, Sarpong T, Quansah DY, Amankwaa I, Boateng D. Barriers to early presentation and diagnosis of breast cancer among African women living in sub-Saharan Africa. PloS One. 2017; 12(2):e0171024. doi: https://doi. org/10.1371/journal.pone.0171024 